This item was submitted to Loughborough's Research Repository by the author.

Items in Figshare are protected by copyright, with all rights reserved, unless otherwise indicated.

\title{
'Pretty Lights' and Maths! Increasing student engagement and enhancing learning through the use of electronic voting systems
}

PLEASE CITE THE PUBLISHED VERSION

http://www.sciencedirect.com/science/article/pii/S0360131509000165\#secx1

PUBLISHER

(C) Elsevier

VERSION

AM (Accepted Manuscript)

LICENCE

CC BY-NC-ND 4.0

\section{REPOSITORY RECORD}

King, Samuel O., and Carol L. Robinson. 2019. "'pretty Lights' and Maths! Increasing Student Engagement and Enhancing Learning Through the Use of Electronic Voting Systems". figshare.

https://hdl.handle.net/2134/8778. 
This item was submitted to Loughborough's Institutional Repository (https://dspace.lboro.ac.uk/) by the author and is made available under the following Creative Commons Licence conditions.

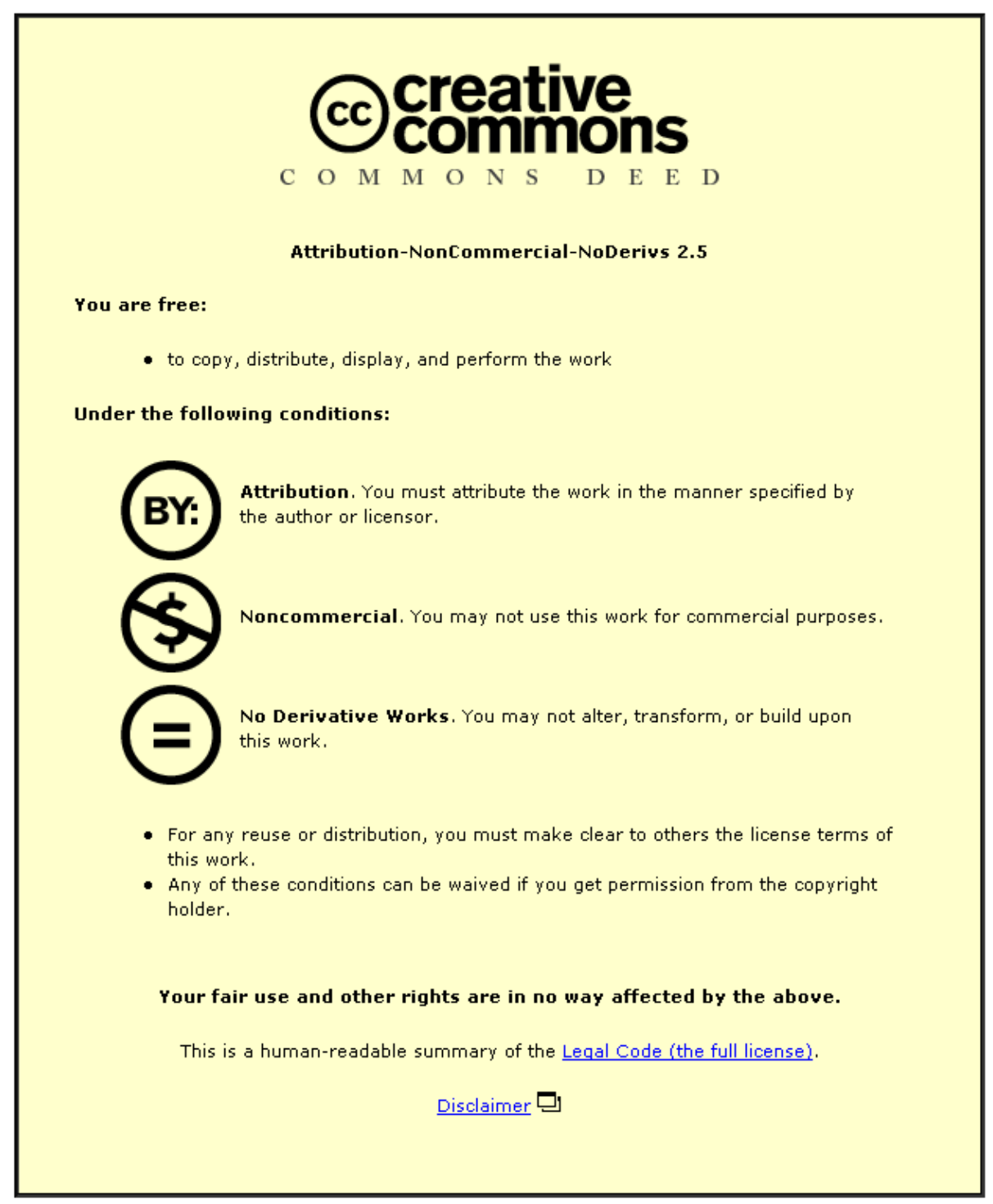

For the full text of this licence, please go to: http://creativecommons.org/licenses/by-nc-nd/2.5/ 


\title{
'Pretty Lights' and Maths! Increasing student engagement and enhancing learning through the use of electronic voting systems
}

\author{
Samuel O. King and Carol Robinson \\ Mathematics Education Centre, Loughborough University \\ Loughborough, LE11 3TU, England \\ Tel: 44 1509222877; Fax: 441509228211 \\ Email: S.O.King@lboro.ac.uk; $\underline{\text { C.L.Robinson@lboro.ac.uk }}$
}

\begin{abstract}
University classes in Mathematics are traditionally perceived to be uninspiring and devoid of active student-lecturer communication. Large undergraduate classes further compound the difficulty of engaging students and enabling viable student-lecturer feedback. At the Mathematics Education Centre, Loughborough University, some staff members have been using electronic voting systems (EVS) to enliven the classroom and enable large numbers of students to respond to questions in real time during class. In this paper, we present an evaluation case study, based on student perceptions, of the impact of EVS use on student learning and engagement. The results show that majority of students are hugely positive about the usefulness and overall advantageousness of EVS use in classes. Results also show that EVS use does increase the likelihood of students participating and engaging in class, as even students who do not view EVS as being particularly useful stated that they are more likely to participate in classes where EVS are used than otherwise. However, there seems to be no correlation between EVS use and improvement (or otherwise) in student grades.
\end{abstract}

Keywords: improving classroom teaching; evaluation of CAL systems; interactive learning environments; media in education; multimedia/hypermedia systems

\subsection{Introduction}

Across university campuses in the UK and elsewhere around the world, academic staff share similar concerns about the nature of contemporary student teaching and learning. These concerns include the fact that classes are bigger, with sometimes upwards of 100 students; students seem distracted and unmotivated in class, and for subjects like Mathematics which can sometimes be abstract, perceived student passivity is often worse. The larger class sizes have made it easier for students to become 'anonymous', and it is a challenge for shy students to participate in class by, for instance, responding verbally to a question. In a bid to address some of these concerns, a number of student-focused learning approaches including Peer Instruction (Crouch \& Mazur, 2001), Just in-time Teaching (Novak, Patterson, Gavrin \& Wolfgang, 1999), and Classwide Discussion (Dufresne \& Gerace, 2004) are being implemented. At the heart of these learning approaches is often a technology known as electronic voting systems (EVS), classroom communication systems, student response systems or simply, handsets (US: clickers). 


\subsection{EVS Technology}

EVS is a technology that affords a lecturer the means to give students, especially in a large class, the chance to engage with course material by having them answer questions in class - with immediate feedback provided. There are two broad types of EVS systems in use - infra red EVS and radio EVS. Infra red EVS has a limited range - that is, such systems can only be used with classes of a predetermined capacity, usually under 100 students. Radio technology is much more robust and can be used in classes with more than 1000 students, depending on the institutional need and the EVS vendor capacity. The most common EVS systems include Turning Point ${ }^{1}$, InterWrite PRS, and Educlick. An EVS (radio) system usually consists of handsets (Figure 1), a receiver and the operating software. In the UK, a handset costs between $£ 30-£ 50$, while receivers range from $£ 200-£ 300$. Some vendors, such as Turning Point, supply the operating software free (see the following references for cost, functionality and usability comparison of the EVS handsets currently available: Wilson, 2006; Draper, 2008).

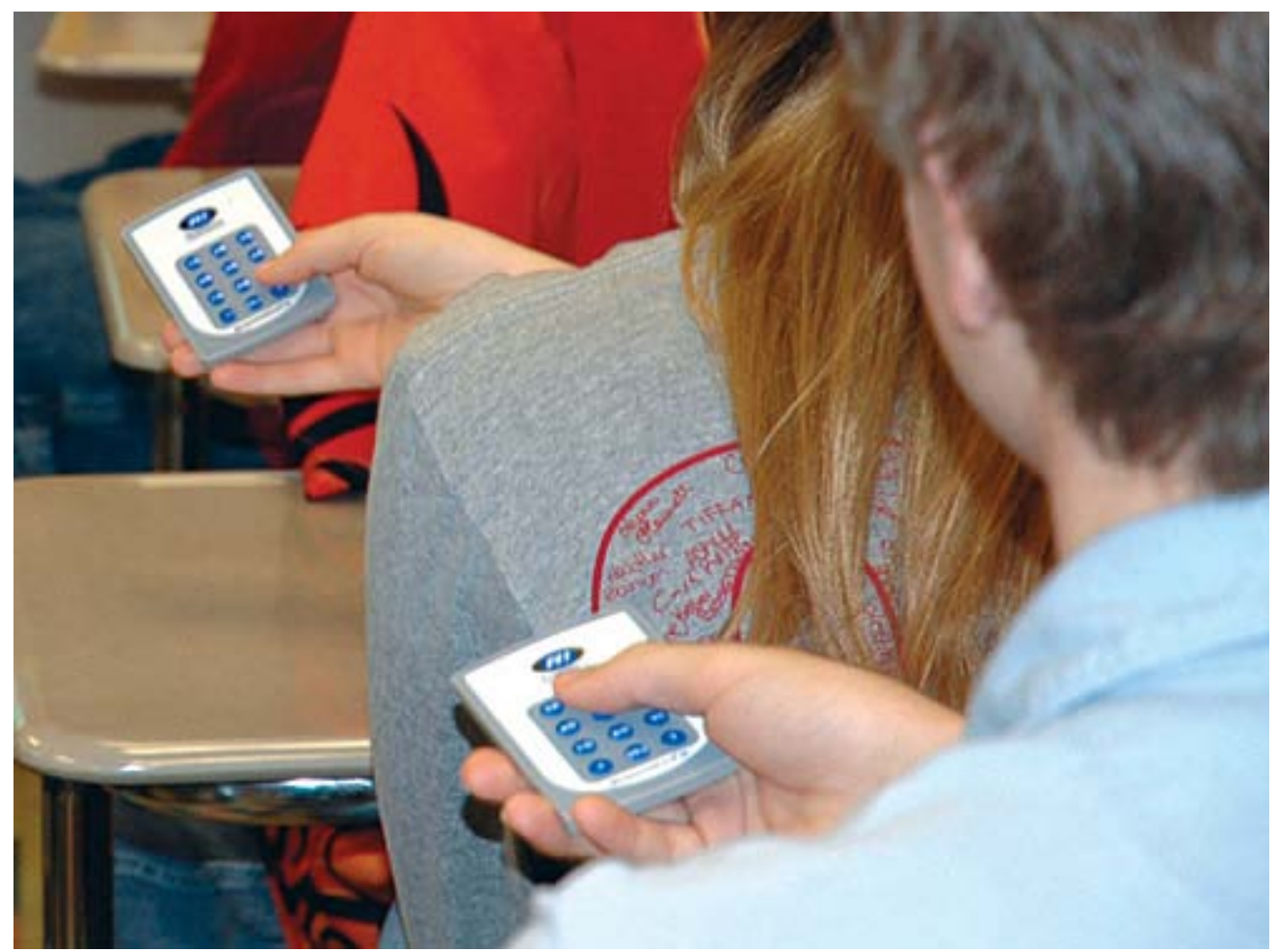

Figure 1 Students using Turning Point handsets to register their responses to a question in class

Based on current practice in the US and UK, there are three modes of EVS acquisition and use in university classrooms. In the US (e.g. Purdue University and University of Wisconsin-Milwaukee), the model is for students to purchase their own handsets at the beginning of a semester, so each student has a personal handset. In the UK, students are usually not required to purchase their own handsets, but there may still be student ownership, depending on institutional practice. At Surrey University for example, students are required to borrow handsets from the library and keep for use for the duration of module(s), usually a semester, where handset use is required. Hertfordshire University also operates a student-ownership model. At Glasgow and

\footnotetext{
${ }^{1}$ http://www.turningtechnologies.co.uk/
} 
Loughborough Universities, however, student ownership of handsets is on lecture-bylecture basis. This means that students collect handsets at the beginning of a lecture where handsets will be used, and then return the handsets at the conclusion of the lecture. But the common element to EVS acquisition in the UK is that the appropriate university department, such as Teaching Support at Loughborough University, usually purchases the handsets. Departments and staff within the institution are then invited to apply for the use of the handsets.

At the Mathematics Education Centre (Loughborough University), Turning Point (TP) supplied the EVS handsets being used by staff from the Centre, and the way TP works is that the enabling software is embedded in Microsoft PowerPoint. So a lecturer can prepare multiple-choice questions (MCQ's) as a series of PowerPoint slides which students respond to by clicking the corresponding alphanumeric answer choice on their handsets (Figure 1). Student responses are then displayed on a PowerPoint slide in the form of a suitable (bar, histogram, pie, etc) chart. The lecturer may then decide to elaborate on any relevant issues arising out of the question and answer display session. For instance, a lecturer should address why option (a) in Figure 2, which $36 \%$ of the students in a class had selected as the correct option, is in fact incorrect.

\section{Which diagram best represents the region of integration of

$$
\int_{0}^{1} \int_{y}^{1}(y+x) d x d y
$$

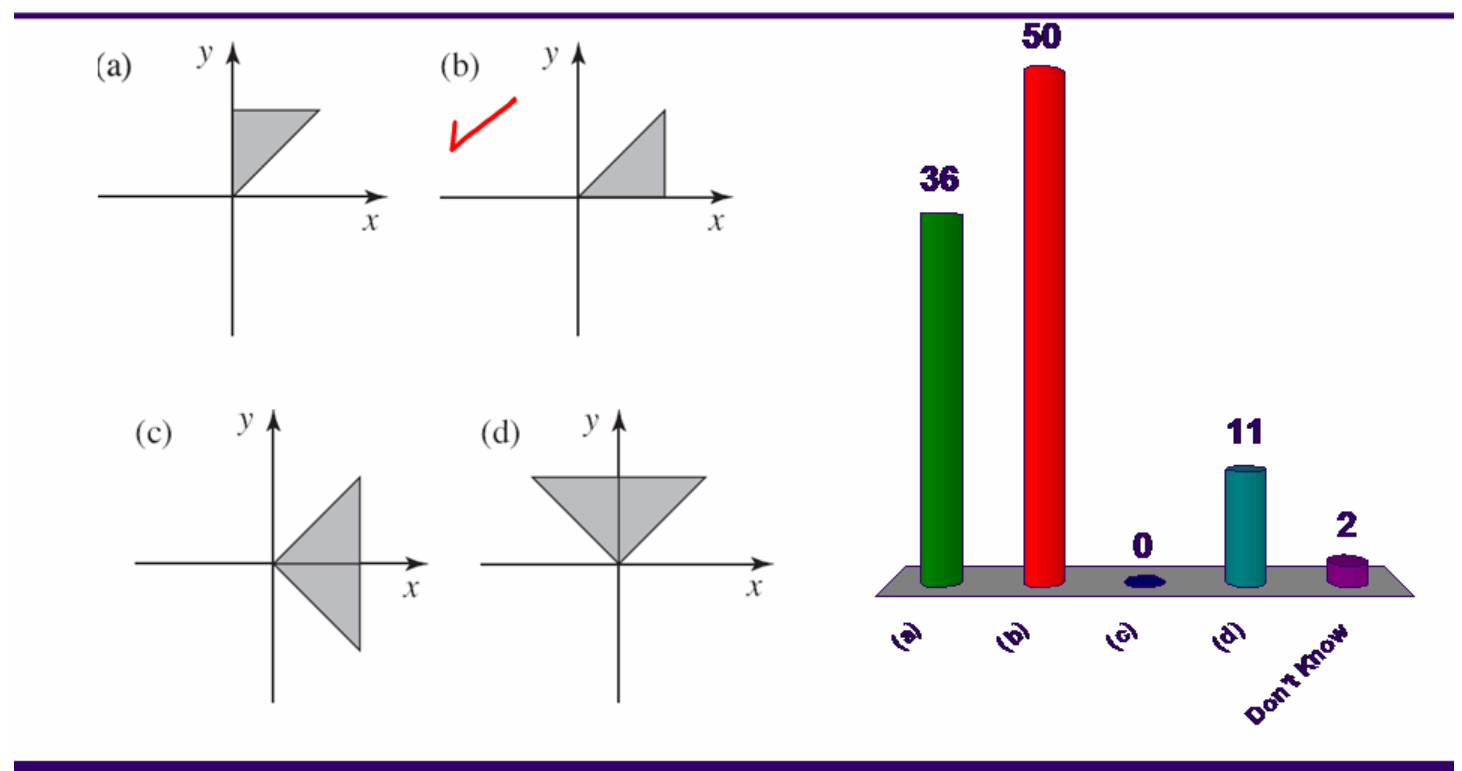

Figure 2 Chart showing student response to a question on integration, with one of the options (option a) highlighting a common student misconception about double integrals

\subsection{Scope}

The research described in this paper was designed as a case study to investigate the use of handsets by staff from the Mathematics Education Centre (MEC) at Loughborough University to teach Mathematics to undergraduate Engineering students. There are three research objectives for this case study:

1. To obtain student views about the usefulness (or otherwise) and impact of handset use on learning 
2. To probe the impact of handset use on student engagement (as measured by in-class student participation rates)

3. To measure the impact of handset use on student academic performance The reason we adopted a case study approach was to determine whether the findings described in research literature about the potential benefits and usefulness of EVS use would apply within the context of engineering mathematics at Loughborough University.

The unique contributions of this research include:

- Conduct of an empirical study to investigate the relationship between student response rates when handsets are used compared with other common student response solicitation methods

- Illumination on how handset drawbacks influence the perceived usefulness of handsets as well as the 'overall advantageousness' of handset use

- Highlighting of the (initial) impact of EVS use on student academic performance, attendance and retention

- Integration of research data from multiple sources including surveys, observations, staff views, and course information, based on a mixed-methods approach. A critique of research on EVS is the tendency for such research to report findings based on a single data source (Fies \& Marshall, 2006)

- A focus on the use of handsets in the formative assessment mode (King, Davis, Robinson \& Ward, 2008) for the teaching of Mathematics

The structure of the paper is as follows: Sections 2 and 3 are devoted to the presentation of the literature review and methodology respectively, while Section 4 focuses on the presentation of results and associated data analysis. Section 5 is the conclusion while future work is the focus of Section 6.

\subsection{Literature Review}

A wide array of literature that includes two books - Banks (2006) and Duncan (2005) - exists on the use of handsets in the US, UK and other countries. So this section will focus on the review of two broad groups of publications that have been written on use of handsets in university education. First, there will be a review of the publications that have quintessentially been literature reviews of papers that have been published on the use of handsets. Second, there will be a review of a cross-section of papers that have focused on reporting evaluations of student perceptions of handset use.

Caldwell (2007), a review of existing literature on handset use, is a comprehensive and detailed work that covers every aspect of handset use including description of the technology, use of questions, effect on student performance and association of handsets with 'peer learning'. The study also includes guidelines for writing good questions and best practice tips. Caldwell however claims that "...much research remains to be done to elucidate the reasons why handsets are effective" and also that "...the research so far is not systematic enough to permit scientific conclusions about what causes the benefits". Simpson and Oliver (2007) categorises the literature on handsets, based on the maturity and increasing depth of research publications, into two timelines: (I.) Pre-2002 and (II.) Post-2002 (2002 - 2006). Distinctive contributions of this paper include the propositions that "Voting systems are best understood as a tool rather than a teaching approach", a view also supported by Fies and Marshall (2006). The authors however cautioned that practice and research into 
handset use has tended to remain "...in the preserve of the enthusiast”, without much emphasis on how the use of handsets “...impact on learning and net benefit”.

The goal of the Fies and Marshall (2006) publication was to highlight the areas of handset research that require increased focus or greater depth. These areas include the adoption of more rigorous methodologies, study of effect of handset use by diverse student populations and increased emphasis on the evaluation of benefits of handset use in "group discussion" mode. In Roschelle, Penuel and Abrahamson (2004), the authors present a theoretical approach code-named CATAALYST, which is based on a formative assessment framework. The authors claim that the CATAALYST approach "improves achievement" and they also use motivational goal theories to explain how the approach "creates greater engagement and broader participation". In Simpson and Oliver (2002), the authors identify, based on literature review, three key measures (of what "counts as good learning") to use in evaluating the effectiveness of handset use. These measures are: The inadequacy of the lecture format as a medium for mere 'content transmission'; active engagement; and quality feedback. Further, the paper lists six benefits that may accrue with the use of handsets while also identifying 12 ways in which handsets have been used.

Publications focussing on student perceptions of handsets use include Zhu (2007), which was based on a study of the use of handsets at the University of Michigan. In contrast to the Simpson and Oliver (2002) study, Zhu identified seven ways in which faculty use handsets and also proffered a list of 14 recommendations on how to use handsets. The MacGeorge, Homan, Dunning, Elmore, Bodie, Evans et al. (2007) study on the other hand adopted a "multi-survey" design that tracked student responses over the course of a semester while the effect of student diversity on perceptions of handset use was also measured. The authors also stressed that the impact of instructor approach to the use of handsets requires further research. Similarly, Kaleta and Joosten (2007) sought to measure student attitudes as well as the impact of handset use on grades and retention at the University of Wisconsin. The reported findings are consistent with those reported elsewhere in that student attitudes were generally positive - with slight improvements and reductions in grades and retention respectively. In Cline, Zullo and Parker (2006), the author describes the use of coloured cards to stimulate engagement and 'peer discussion' in his classes and then contrasts this approach with the functionality afforded by the use of handsets, which were later introduced into the author's classes.

The following publications have a specific focus on the use of EVS to stimulate peer instruction or classwide instruction as an alternative to the traditional lecture format which is low on interactivity (Dijk et al., 2001), but high on content: Mazur (1997), Hake (1998), Draper and Brown (2004), Boyle and Nicol (2003), and Fagen, Crouch and Mazur (2002). Papers that have been published by UK-based academics include Nicol and Boyle (2003), Cutts, Kennedy, Mitchell and Draper (2004), McCabe, Heal and White (2001), and Draper, Cargill and Cutts (2002). Further, electronic resources with comprehensive information on the use of handsets include the Vanderbilt University portal ${ }^{2}$ and the repository created by Stephen Draper ${ }^{3}$ of Glasgow University.

\footnotetext{
${ }^{2}$ http://www.vanderbilt.edu/cft/resources/teaching_resources/technology/crs.htm

${ }^{3}$ http://www.psy.gla.ac.uk/ steve/ilig/
} 


\subsection{Methodology}

This section describes the methodology adopted in the design and execution of this case study.

\subsection{Sample}

145 undergraduate students drawn from the Automotive, Aeronautical and Mechanical Engineering departments who are in their second year of study participated in this study (see Figure 3 for sample composition by department) - the total class size was 250 students. As this study was designed to look at the impact of handsets on learning Mathematics at Loughborough University, these students were selected because they are a group of students who have been taught Mathematics with the aid of handsets. 145 students (representing $58 \%$ of the class) completed a main questionnaire on the use of handsets. In addition 120 students, drawn from the base class size of 250 students, (some of these 120 students are also part of the cohort of 145 students who later completed the main questionnaire), completed the one-minute questionnaire (see Section 3.2). Both questionnaires were administered in the first semester of the 2007/2008 academic session.

It should be stated here that the views of the students who participated in this study might not depict with complete accuracy the views of the typical Engineering student at Loughborough University. This is because students in the Automotive and Aeronautical Engineering departments are viewed as above average, having obtained grade 'A' (Distinction) or ' $\mathrm{B}$ ' in Mathematics as requirement for admission into university.

\subsection{Methods}

This study adopted the mixed-methods research protocol, which consists of the following methods:

Observations: The authors sat in on classes and observed the influence or otherwise of the use of handsets on teaching and learning in the classes where handsets were used. The observations were initially open-ended, with the aim of going into classes simply to learn and record observations, and therefore not pre-empting findings or introducing preconceptions about handset use into the observation process.

From the initial open observations, the authors were able to collect data that subsequently informed later class observations. So the latter observations included watching out for the quantity, time and purpose of the questions used, student response and/or enthusiasm, TP equipment setup and functionality. 


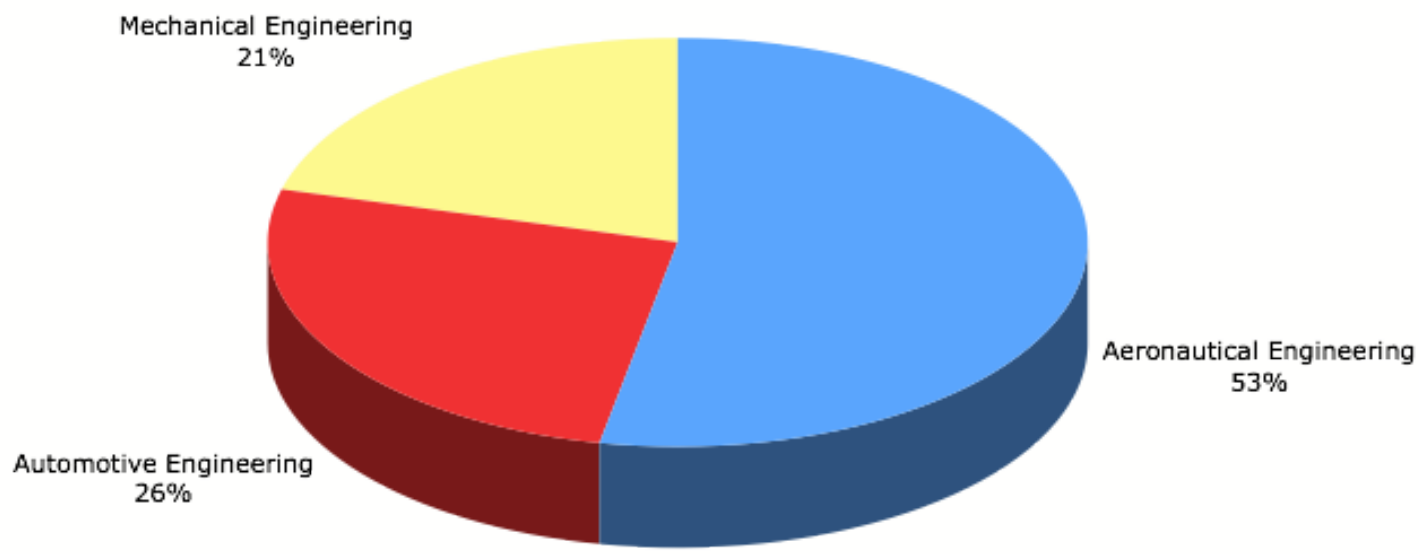

Figure 3 Chart showing the Engineering departments that the students who participated in this study are drawn from

One-Minute Questionnaire (OMQ): Based on the one-minute paper concept (Angelo \& Cross, 1993), this questionnaire was administered to students with one purpose in mind: To get them to list what they perceived as the pros and cons of handset usage. Further, students were given less than 120 seconds to complete the open-ended questionnaire, so as to get them to write down the issues that were uppermost in their minds, without giving it too much thought. Instances where data from the OMQ provide additional insights on a subject (finding) are highlighted in relevant subsections of Section 4.

Informal Feedback: There were informal discussions with individuals and groups of students, usually after classes where handsets had been used, soliciting their opinions on the benefits or otherwise of handset usage. For instance, a common question students were asked during the informal exchanges is, What's your opinion on the use of handsets in lectures?

Main Questionnaire: All 145 students who participated in this study completed a detailed, 13-item questionnaire which was created using the service provided by Bristol University ${ }^{4}$. The data presented in this study is based on student responses to this questionnaire, supplemented with data from observations, OMQ, and informal feedback. This questionnaire was piloted with 35 students (drawn from the base class size of 250 students) before the final version, which incorporated feedback from the trial version, was administered to the cohort of 145 students cited above.

\footnotetext{
${ }^{4}$ http://www.survey.bris.ac.uk/
} 


\subsection{Results, Analysis and Discussion}

The analysis of the data from the main questionnaire, supplemented with information from observations, the OMQ and informal feedback is presented in this section.

\subsection{Benefits}

To determine which attributes of handset use students found the most beneficial, students were given a list of seven benefits on the main questionnaire and asked to rank the three benefits that they considered the most important in the order: $1^{\text {st }}, 2^{\text {nd }}$ and $3^{\text {rd }}$. The benefits were derived from literature review, including some from a questionnaire that had been used at Glasgow University ${ }^{5}$. The ranking of the benefits by the respondents is shown in Table 1 . The final rankings were derived by assigning 3 points for each placement of a benefit in the ' 1 st, category, 2 points for the ' 2 nd' category, 1 point for the $3^{\text {rd }}$ category, and 0 points if a benefit was not placed in any of the $1^{\text {st }}, 2^{\text {nd }}$ or $3^{\text {rd }}$ categories. This ranking method was adopted because it validated one of the other two methods that had been implemented but later discarded. The other methods were: (1) Selecting the 3 benefits that had the highest total number of student responses - this method returned the same results as the one adopted above (2) Selecting the 3 benefits that were selected most frequently in the $1^{\text {st }}$ category

\begin{tabular}{|l|l|}
\hline Position & \multicolumn{1}{|c|}{ Benefits } \\
\hline $\begin{array}{l}1^{\text {st }} \text { (most } \\
\text { important) }\end{array}$ & $\begin{array}{l}\text { Checks whether I'm understanding course material as I thought I } \\
\text { was }\end{array}$ \\
\hline $2^{\text {nd }}$ & Allow learners to identify problem areas \\
\hline $3^{\text {rd }}$ & It makes lectures more interactive \\
\hline $4^{\text {th }}$ & Makes me think more about the course material during lectures \\
\hline $5^{\text {th }}$ & Gives me an idea of well everyone else is doing \\
\hline $6^{\text {th }}$ & Allows me to answer privately without others knowing how I voted \\
\hline $7^{\text {th }}$ & It's fun \\
\hline
\end{tabular}

\subsubsection{Top Three Benefits}

The top three benefits identified from the ranking exercise point to a very important role that handsets play, namely that they have the potential to "...alter the very basis of classroom dynamics by giving students, in large lecture based classes, the power of individual feedback and motivation" - AP (2005) as quoted in Barnett (2006). But because the literature is saturated with (often superficial) focus on the 'feedback' attribute of handsets, it is easy to ignore or 'pass over' the role that feedback plays in student learning. Feedback can empower students in the following ways:

1. It is instant

2. It is a barometer for personal understanding of study

3. It enables the individual student to gauge the ability level of the class and subsequently peers at a given point in class

4. It can often be reassuring especially when students know they are not the only ones giving 'stupid' answers.

\footnotetext{
${ }^{5}$ Dr. Margaret Brown of the University of Glasgow kindly gave us permission to reuse a couple of questionnaire items
} 
The formative feedback that the use of EVS engenders is pivotal in the learning process (Nicol \& Macfarlane-Dick, 2006). The effective use of EVS provides staff with the knowledge of what needs to be corrected and what needs to be reinforced in student learning (Russell, 2008). Staff who do not have 'a sense' of how much students know or a means of gauging, week by week, student assimilation of the material they have been taught in class, cannot correspondingly make the necessary pedagogical changes in order to address identified gaps in students understanding. Moreover, prompt formative feedback also catalyses some form of dialogue (Laurillard, 2002), which is usually non-existent in a traditional lecture format, between the teacher and the associated learners.

\subsubsection{Fun}

It is poignant to point out that although 'fun' was ranked last by students (Table 1), this may not be an accurate reflection of the importance the modern student accords the role that fun plays in the learning process. The modern student experience is replete with fun-based activities such as video and interactive games, with some of these games having overt educational overtones. However, university (especially Mathematics) learning may not exactly be characterized as fun, as students are expected to display a serious and disciplined approach to learning. But it might be argued that the current generation of students may well better respond to instruction if they perceive the learning context as having an element of fun. Indeed, some of the student submissions to the OMQ, as indicated by the sample below, support this claim:

It's fun to press the buttons and make the pretty lights flush and the numbers go up [Turning Point handsets flash green when a handset is functional and red when it is not]

It's fun, so helps make the lecture more fun

[Handset] Has pretty lights

It is inconceivable that any self-respecting lecturer would consider any of the attributes of handsets as expressed in the comments above as beneficial to learning. But from a student perspective, the "pretty lights" may have kept them awake and thus available for the learning activity taking place in the classroom.

\subsubsection{Other Beneficial Themes Identified}

The other submissions from the OMQ identified the following themes (apart from fun) as being most important to students:

- Theme 1 - I am not stupid because other students also got answers wrong: "Reassures you there's always someone more stupid than you"; If you get it wrong no one knows you're stupid"

- Theme 2 - Feedback: "Lets you know [how] well you are understanding the material as it's taught”; "Can see how well I am doing'

- Theme 3 - Problem identification: "Shows where I need to work more"; "Allows lecturer to know if students are understanding material and hence what to re-cover"

- Theme 4 - Engagement/Interactivity: Keeps people awake due to being interactive"; "Keeps people awake and attentive during lectures"; "Allows 
students to interact with lecturers more"; "Allows interaction between students and lecturers"; "Stops boredom. Keeps people awake"

- Theme 5 - (Anonymous) Participation: "Gets you involved with the lecture”; "Your [i.e. you are] not afraid to give an answer"

It should be noted that these themes from the OMQ instrument, apart from Theme 1 ("I am not stupid..."), are generally congruent with (the themes underpinning) the benefits identified from the main questionnaire (Table 1). The top three benefits identified in Table 1 are, for instance, consistent with Theme 2 (Feedback), Theme 3 ('Problem Identification') and Theme 4 ('Engagement/Interactivity') respectively. The consistency of the results derived from the two different instruments thus confirms that the same benefits that have accompanied EVS use in other institutional domains (e.g. Draper et al. 2002; Kaleta \& Joosten, 2007) have generally been experienced within the Loughborough University EVS usage context.

\subsection{Handset Drawbacks}

Responses to a main questionnaire item on the perceived disadvantages of handset use shows that two main drawbacks were identified - handsets sometimes do not work (78 students) and it takes time to set up the systems for use in class (42 students). These drawbacks have to do with setup and operational issues which can be more readily overcome as staff competence and confidence in using handsets increase with time. To determine the impact of these two drawbacks on the perceived usefulness of handsets, the responses of students who had identified these drawbacks were correlated with their responses to the item on usefulness of handsets (Figure 4). The results show that 35 students or $83 \%$ of those 42 students who said handsets "take time to set up" also said that they are "useful or very useful", while 65 students or $83 \%$ of those 78 students who complained that handsets sometimes 'don't work' also said they found handsets 'useful or very useful'. These results further support the notion that the identified drawbacks were not considered sufficient by most of the participating students for them to significantly alter their positive perceptions of handset usefulness. 


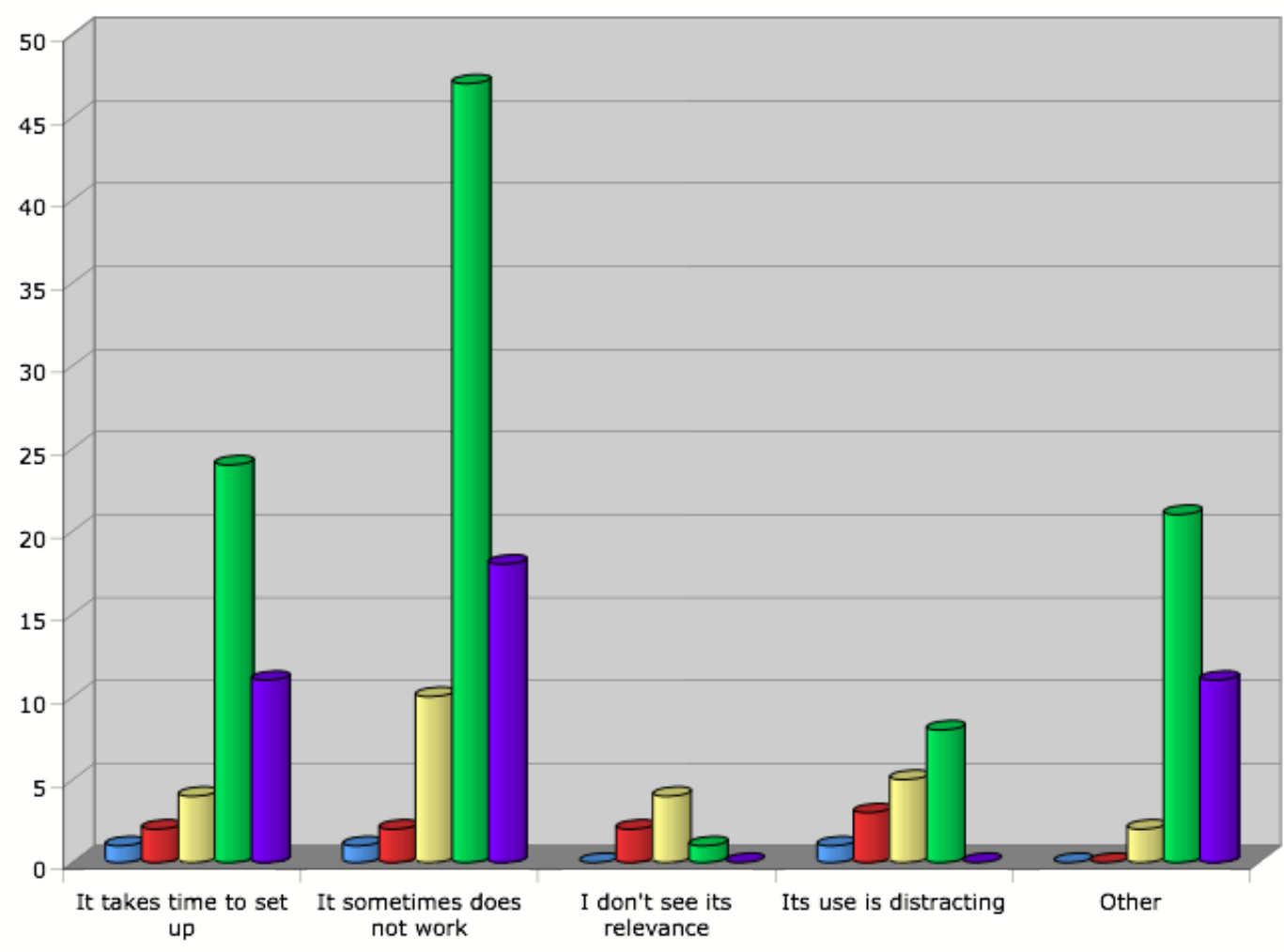

Not at all useful

Figure 4 Impact of handset drawbacks on its perceived usefulness

In contrast to the main questionnaire where students were given a list of disadvantages to select from, the OMQ instrument was open-ended as students were simply asked to list what they considered the disadvantages ('cons') of using handsets. Again, the top two concerns were "Doesn't always work" and "It takes up time". The other two drawbacks that came up, with much lower occurrence, were "Used too often" and "Guesswork”.

\subsection{Usefulness and Overall Advantageousness of Handsets}

In response to a question on how useful students found the handsets, $57.9 \%$ of students said they found handsets 'useful' while $22.8 \%$ found them 'very useful'. So $80.7 \%$ or 4 out of 5 students found the handsets generally useful (Figure 5). Only $4.8 \%$ of students found the handsets either 'not at all useful' or 'not very useful'. However, $14.5 \%$ of the respondents responded to this question by selecting the 'neutral' option provided. There was also a main questionnaire item to determine whether students have, overall, found the use of handsets advantageous to their learning - taking into consideration the benefits, drawbacks and perceived usefulness of handsets. So the item on the overall advantageousness of handsets was deliberately positioned to appear after students had had a chance to response to the main questionnaire items on the benefits, drawbacks and usefulness of handsets. 


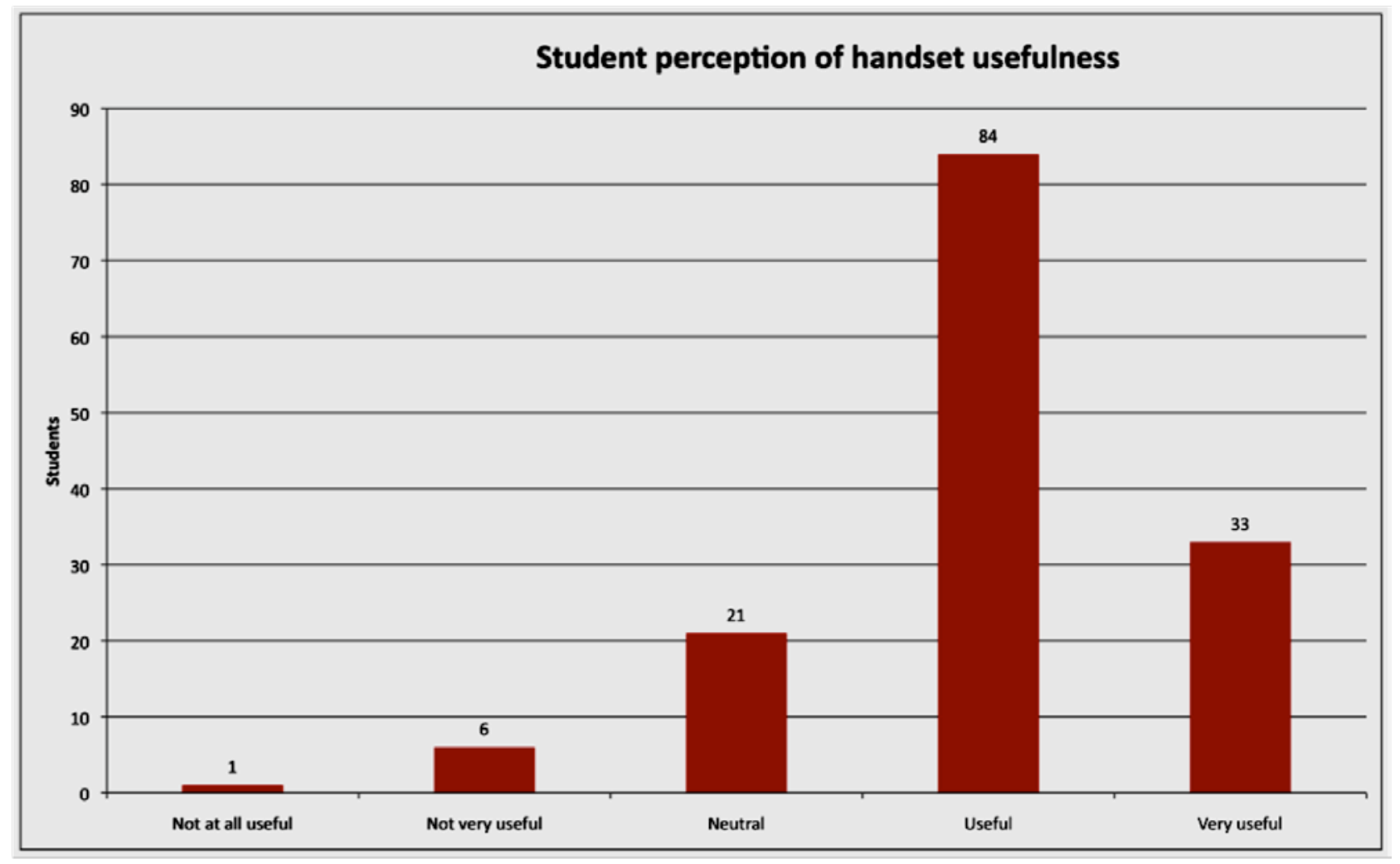

Figure $580 \%$ of students said EVS are 'useful' or 'very useful'

Student responses to the questionnaire item on the 'overall advantageousness' of handsets, when correlated (Figure 6) with earlier submissions on how 'useful' they found voting systems, indicate a consistent pattern: students who found the handsets useful similarly said that the advantages outweigh the disadvantages. This is because $80 \%$ of students said handsets were either 'definitely advantageous' or that 'advantages outweigh disadvantages' while $15.9 \%$ of students selected the 'neutral' option. But submissions from 2 students indicated that although they considered handsets 'useful', the 'disadvantages [still] outweigh the advantages'. Further, submissions from 7 students who stated that they were "neutral" about the overall advantageousness of handsets had earlier stated that they considered handsets 'useful'. 


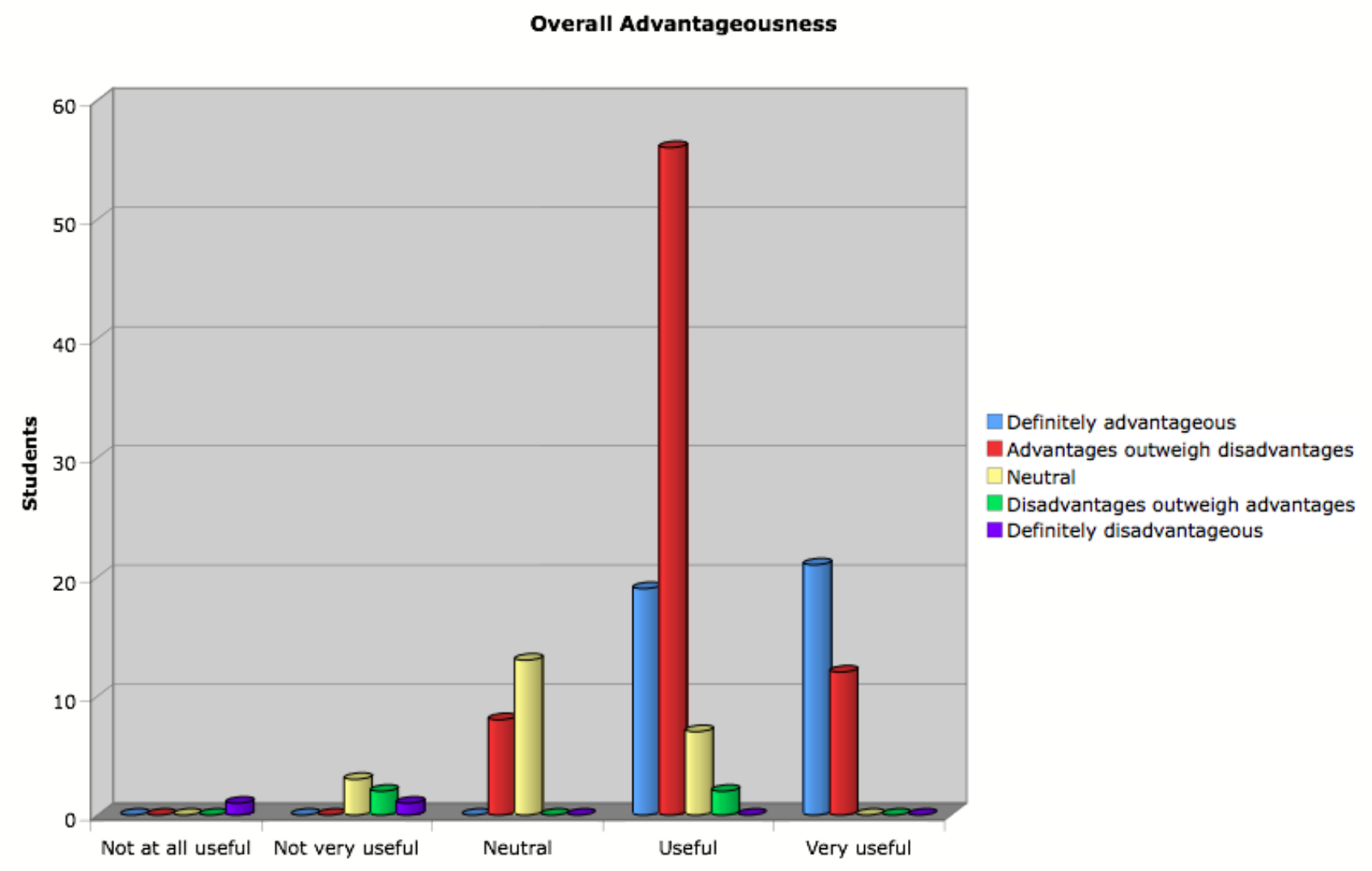

Figure 6 Overall advantageousness of handset use

\subsection{Impact of Handsets on Participation Rates}

To evaluate whether handset use had significant advantages over other methods that are usually used to solicit student response in class, students were asked to specify how likely they were to respond when handsets are used compared to raising of hands or giving a verbal response. Student submissions clearly show that the use of EVS predisposes at least three-quarters of all students (84.61\%) towards answering questions in class, compared to (28.67\%) when students are asked to respond by raising their hands or (12.59\%) when they are asked for a verbal response (Figure 7). 


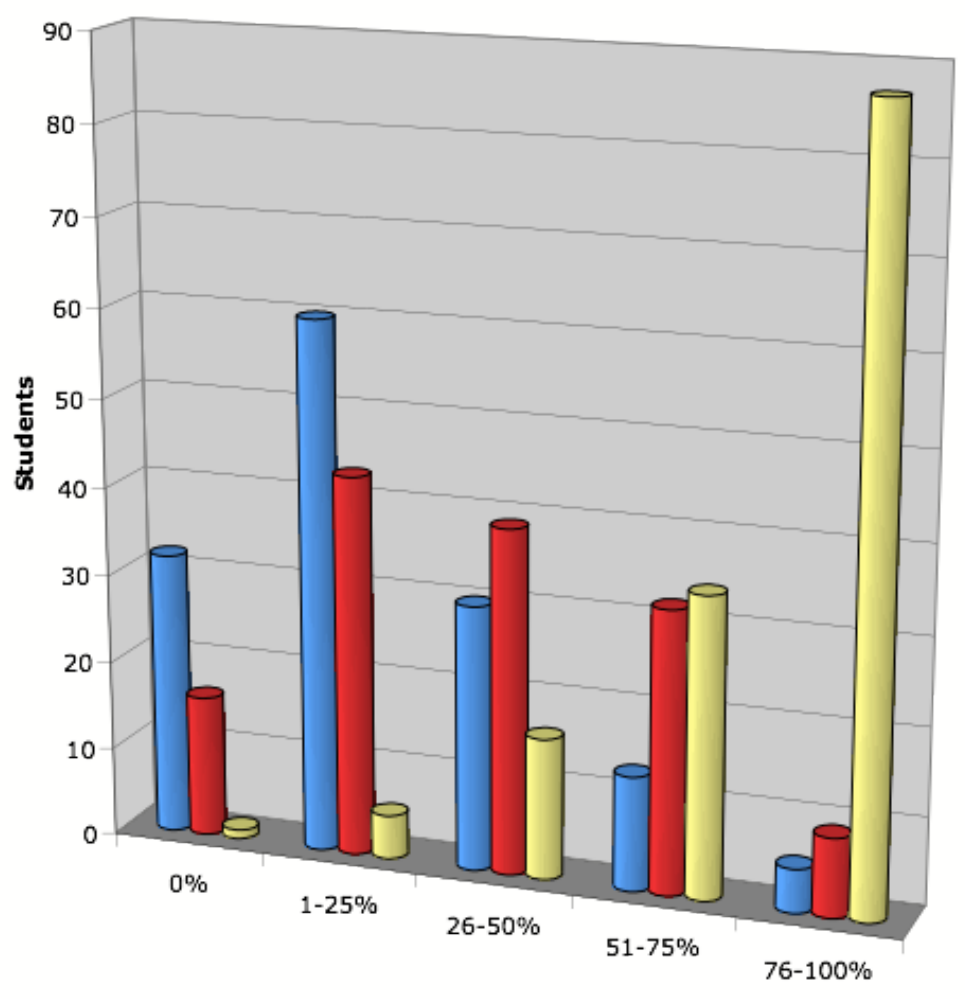

Figure 7 Comparison of two other student solicitation methods with handsets

To measure the relationship the between in-class student response rates and handset use, students were asked to select the likelihood (in percentage) of them responding to a question in class. Data results show that 4 out of 5 students indicated that, when handsets are used, there is at least a $50 \%$ likelihood that they will respond to a question in class. This is so because $37.9 \%$ and $46.2 \%$ of students indicated that their likelihood of participating in a class where handsets are used are $51-75 \%$ and $76-100 \%$ respectively. Moreover, even the students who are not sure about the usefulness of handsets are more likely to answer questions in class when they are provided with handsets (Figure 8). Data analysis shows $71 \%$ of students who said they are 'neutral' as well as $57 \%$ of those who rated handset usefulness as either 'Not at all useful' or 'Not very useful' indicated that there is at least a $50 \%$ likelihood that these same students will participate in a class due to handset use. 


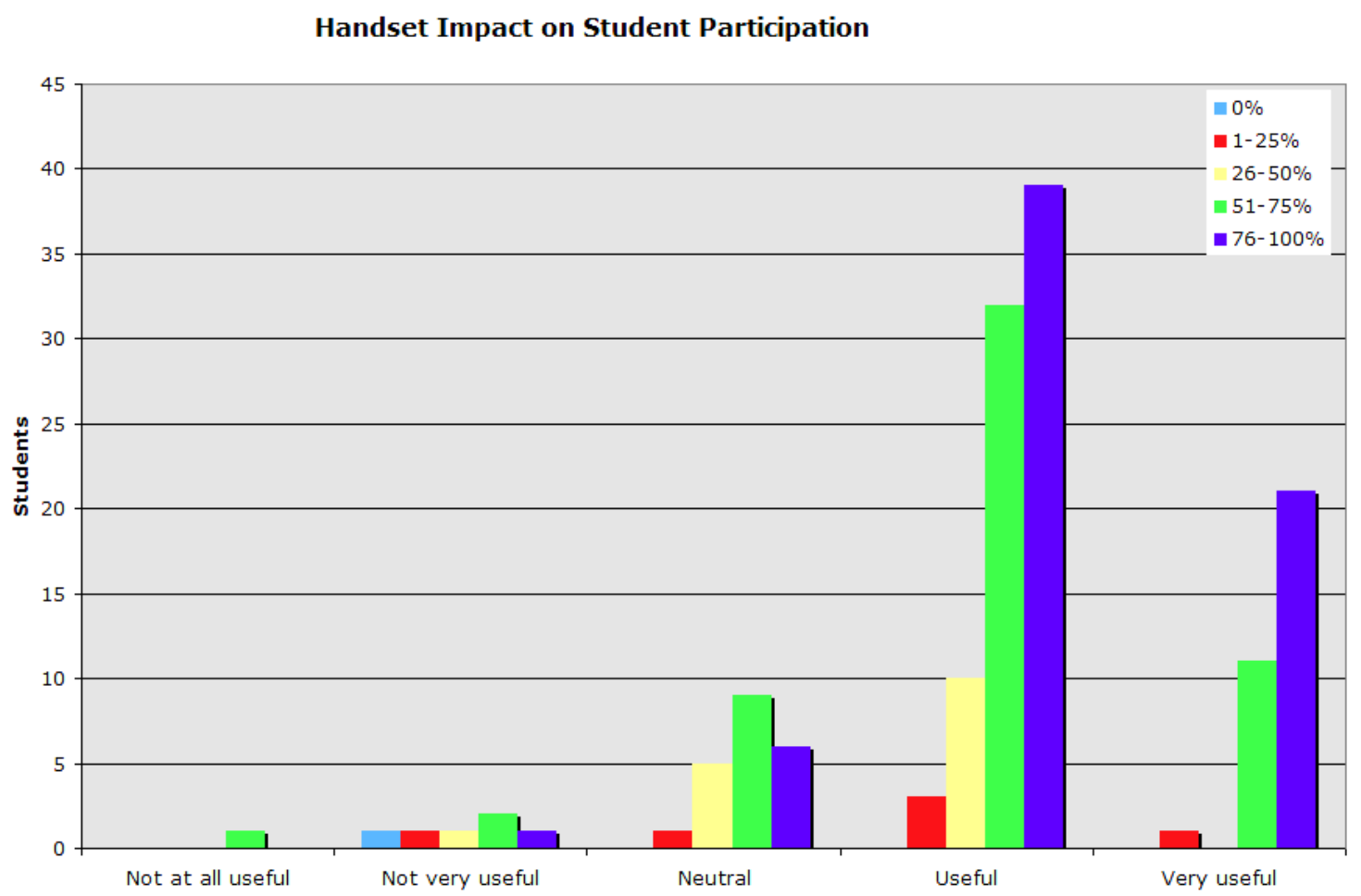

Figure 8 Impact of handsets on student participation rates in class

\subsection{Reasons for Non-Participation}

From class observations, it was apparent that a small subset of students did not appear to be participating in class. So one of the main questionnaire items included a question designed to provide answers to reasons why some students may have not used their handsets to participate in class. Survey data shows that 3 out of 5 (59.3\%) students sometimes did not use the handsets provided to respond to questions in class. The top three reasons for this behaviour are 'insufficient time allocation for working out problem' (65.11\%); ; 'handset did not work' (30.23\%); and 'did not collect/have a handset '(27.91\%).

The time given for answering a question, from class observations, normally ranges from 30 to 120 seconds, depending on the topic and complexity of the problem. Thus time allocation for working out Mathematics solutions may be insufficient, especially for the 'slower' students. However, time allocation has to be balanced with moving the lecture along at a steady pace such that undue focus is not put on either the 'faster' students who usually turn in their answers quickly or the 'slower' students who require more time. Moreover, a student who had a fast turnaround time to one question may find another more demanding, and thus requiring more time.

Second, the EVS setup at Loughborough University means that some students may not be able to collect handsets for use in a class. The usual procedure is that students collect a handset as they enter a lecture hall from the front of the class. But some students may choose to enter a hall from the rear, and may not be too bothered about going to the front to collect a handset. In addition, some handsets didn't work and this

\footnotetext{
${ }^{6}$ Note the percentages do not add up because students could select more than one option.
} 
seemed to have been a significant handicap, with 26 students (18\%) responding that the handsets they used had at one time or another failed to work.

Submissions from two students indicated that one of the options for the question on why students did not vote on a question in class should have been inability to work out the problem. The reason this option was left out was because when EVS was used, the lecturer would usually have as an option the item, "I don't know".

\subsection{Timing of Questions}

In response to a question on when best to ask questions, the range of responses indicate that students do not seem to mind when questions are asked - questions may be paced throughout lecture or be asked towards the end. In practice - for instance, see King et al. (2008) - when questions are asked would depend on what the lecturer is aiming to achieve in a particular lecture as well as on the topic and scope of subject.

\section{8 Handsets for Mathematics?}

One of the objectives of this study was to investigate the perceptions of students towards the use of handsets. Although the target students are from Engineering departments, they are being taught Mathematics through the use of handsets. It is therefore important to know whether students think it is appropriate for Mathematics to be taught using handsets. For instance, one of the challenges of using EVS to teach Mathematics is the difficulty of finding relevant questions to use in lectures. And some students had made submissions, in response to the OMQ, such as "Some questions are pointless"; "Lecturer sometimes just asks questions instead of teaching it [the topic]" - suggesting that Mathematics may not be a suitable medium for handset use. However, the overwhelmingly positive response - 88\% of students indicated that they consider EVS 'appropriate' for teaching Mathematics in response to a main questionnaire item - seems a clear verdict that students welcome the use of handsets to teach Mathematics. The predominantly positive perception of the appropriateness of handsets for Mathematics teaching is however in contrast to the ambivalent views some of the Mathematics-teaching staff have towards the use of handsets (King et al., 2008).

\subsection{Staff Views}

In a separate study (reported in King et al., 2008), we surveyed and also interviewed the staff using EVS in a range of disciplines, including Mathematics, Geography, and Human Sciences, at Loughborough University. The findings indicate that the associated staff have positive views about the use of EVS, which is "generally seen as an effective teaching tool as its use can enhance student engagement by increasing their participation in class, give lecturers valuable feedback on student understanding, [and] make the classroom more 'fun'”. However, staff expressed reservations about some of the technical (e.g. operating software quitting unexpectedly, faulty handsets, etc) and pedagogical obstacles (e.g. the learning curve, finding and using good questions, lecture time constraints, etc) that have to be overcome in order to use EVS effectively. 


\subsection{Impact on Student performance, Attendance and Retention}

A critique of research on EVS impact on learning is the tendency for such research to mainly present findings on student attitudes or views of EVS usefulness (Simpson \& Oliver, 2007). In this study, we wanted to determine whether there has been any significant change in the academic performance of students who have been taught using EVS. To do this, we compared the mean academic grades of two cohorts of students on a second-year Engineering mathematics module taught by the same instructor in the 2006/2007 (i.e. 06/7) and 2007/2008 (i.e. 07/8) academic years - see Table 2. The only major difference between the two cohorts of students was that the 2007/2008 cohort was taught using EVS - assessment modes, instructor pedagogical practices, and course curriculum largely remained the same across the two cohorts. The data (Table 2) shows that there was no significant difference in the overall grades of the two cohorts.

\begin{tabular}{|l|l|l|l|l|l|l|l|}
\hline $\begin{array}{l}\text { Cohort's } \\
\text { Coursework Average } \\
\text { (in \%) }\end{array}$ & \multicolumn{2}{l|}{$\begin{array}{l}\text { Cohort's Exam } \\
\text { Average (in \%) }\end{array}$} & \multicolumn{2}{l|}{$\begin{array}{l}\text { Cohort's Overall } \\
\text { Average (in \%) }\end{array}$} & \multicolumn{2}{l|}{$\begin{array}{l}\text { \% of Students } \\
\text { Failed }\end{array}$} \\
\hline $06 / 7$ & $07 / 8$ & $06 / 7$ & $07 / 8$ & $06 / 7$ & $07 / 8$ & $06 / 7$ & $07 / 8$ \\
\hline 81.3 & 58.9 & 59.2 & 62.0 & 63.2 & 60.3 & 13.8 & 14.9 \\
\hline
\end{tabular}

Table 2 Data showing the average grades of students on a second-year Engineering mathematics course at Loughborough University over a two-year period

Further, the '\% of students failed' column (Table 2) indicates that EVS impact on student retention was negligible. Moreover, student attendance at lectures for the 2007/2008 cohort, based on class observations, was no different from attendance patterns for the 2006/2007 cohort. The negligible effect of EVS use on student retention and attendance is in contrast to reports of EVS potential to improve attendance (e.g. Boyle \& Nicol, 2003). However, it would be expedient not to conclude that EVS has no impact on student performance, since pedagogical changes often takes time to translate into concrete results, as measured by improvement in grades. In addition, it takes time to learn how to effectively use and integrate a technological tool into the teaching and learning process.

\subsection{Conclusion}

This case study focused on investigating the views of the affected students about the use of handsets by the MEC staff at Loughborough University in the teaching of Mathematics. The study was designed to:

- Highlight the usefulness (or otherwise) and impact of handset use on learning

- Show the impact of handset use on student participation rates or engagement in class.

- Indicate the impact (or otherwise) of handset use on student academic performance

Students generally have positive views about EVS usefulness, with $80 \%$ of students stating that they found handsets 'useful' or 'very useful'. Although handset use has some drawbacks and not all students have participated by using the handsets in class, yet the consensus, from student responses, is that EVS is seen as being overall advantageous to their learning. The benefits of EVS use that have been identified in research literature, such as feedback and problem identification, were also 
independently confirmed by the students we sampled. Student association of EVS use with fun, and how this may be beneficial to learning has also been highlighted.

The results also show that handset use does increase the likelihood of students participating and engaging in class, as even students who do not view handsets as being particularly useful stated that they are more likely to participate in classes where handsets are used than otherwise. Moreover, the use of EVS has a greater impact on the likelihood of students engaging themselves in a class, compared to other common student response solicitation methods like raising of hands and volunteering a verbal response.

It is apparent from the findings presented in this paper and other research outputs that students display positive attitudes about EVS usefulness. However, the impact of EVS use on academic performance is not yet clear. The results obtained for this study show that EVS use has yet to make any difference to student performance, as measured by mean grades obtained on a mathematics module. Also, EVS use has had a negligible effect on student attention and retention rates. Longitudinal research is required to determine the long-term impact or otherwise of EVS use on student academic performance, using measurable criteria such as course grades.

\subsection{Future Research}

This study has focussed on obtaining the views of students about handset use and associated impact on student learning. We have also investigated the impact of EVS use on student grades and retention. Future research will continue to focus on the relationship between EVS use and academic performance over a two-year period across different modules and cohorts of students at Loughborough University. We also plan to undertake a survey of all mathematics' academic staff in the UK who are using EVS. Another aspect of handset use we plan to investigate are the effects (if any) of instructor approach and repetitive or regular use of handsets on student perceptions of their usefulness or otherwise. Last, we would take a deep approach to investigating how and in what concrete ways the use of EVS has helped or hindered students in learning mathematical subjects such as algebra.

\section{References}

Angelo, T. A., \& Cross, K. P. (1993). Classroom assessment techniques: A handbook for college teachers ( $2^{\text {nd }}$ ed., pp 148-153). San Francisco: Jossey-Bass.

Associated Press (2005). No wrong answer: Click it. Accessed 7th May 2008 from: http://www.wired.com/culture/lifestyle/news/2005/05/67530.

Banks, D. A. (Ed.). (2006). Audience response systems in higher education: Applications and cases. Hershey, PA: Information Science Publishing.

Barnett, J. (2006). Implementation of personal response units in very large lecture classes: Student perceptions. Australasian Journal of Educational Technology, 22(4), 474-494.

Boyle, J. T., \& Nicol, D. J. (2003). Using classroom communication systems to support interaction and discussion in large class settings. Association of Learning Technology Journal, 11(1), 43-57. 
Caldwell, J.E. (2007). Clickers in the large classroom: Current research and bestpractice tips. Life Sciences Education, 6(1), 9-20.

Cline, K., Zullo, H., \& Parker, M. (2007). Using classroom voting in mathematics courses. Paper presented at the 19th Annual International Conference on Technology in Collegiate Mathematics, Boston, MA.

Crouch, C. H., \& Mazur, E. (2001). Peer instruction: Ten years of experience and results. American Journal of Physics, 69(9), 970-977.

Cutts, Q., Kennedy, G., Mitchell, M., \& Draper, S. (2004). Maximising dialogue in lectures using group response systems. Proceedings of the 7th IASTED International Conference on Computers and Advanced Technology in Education.

Draper, S. (2008). EVS technologies, alternatives, vendors. Accessed 5th December 2007 from: http://www.psy.gla.ac.uk/ steve/ilig/tech.html\#Alternative.

Draper, S.W., \& Brown, M.I. (2004). Increasing interactivity in lectures using an electronic voting system. Journal of Computer Assisted Learning, 20(2), 81-94.

Draper, S. W., Cargill, J., \& Cutts, Q. (2002). Electronically enhanced classroom interaction. Australasian Journal of Educational Technology, 18(1), 13-23.

Dufresne, R. J., \& Gerace, W. J. (2004). Assessing-to-learn: Formative assessment in physics instruction. The Physics Teacher, 42, 428-433.

Duncan, D. (2005). Clickers in the classroom: How to enhance science teaching using classroom response systems. San Francisco: Pearson Education.

Fagen, A.P., Crouch, C.H., \& Mazur, E. (2002). Peer instruction: Results from a range of classrooms. The Physics Teacher, 40(4), 206-209.

Fies, C., \& Marshall, J. (2006). Classroom response systems: A review of the literature. Journal of Science Education and Technology, 15(1), 101-109.

Hake, R. R. (1998) Interactive-engagement versus traditional methods: A sixthousand student survey of mechanics data for introductory physics courses. American Journal of Physics, 66, 64-74.

Kaleta, R., \& Joosten, T. (2007). Student response systems: A University of Wisconsin study of clickers. ECAR Research Bulletin, Vol. 2007, No. 10.

King, S.O., Davis, L., Robinson C.L., \& Ward, J.P. (2008) Use of Voting Systems in Lectures at Loughborough University - A Review of Staff Experiences. Proceedings of the Mathematical Education of Engineers (MEE 2008): $14^{\text {th }}$ Joint Conference of Mathematics Working Group (MWG) of the European Society for Engineering Education (SEFI) and the Institute of Mathematics (IMA).

Laurillard, D. (2002). Rethinking university teaching: A conversational framework for the effective use of learning technologies. London: Routledge. 
MacGeorge, E. L., Homan, S.R., Dunning, J.B., Elmore, D., Bodie, G.D., Evans, E., Khichadia, S., Lichti, S.M., Feng, B. \& Geddes B. (2007). Student evaluation of audience response technology in large lecture classes. Educational Technology Research and Development, 56 (2), 125-145.

Mazur, E. (1997). Peer instruction: A user's manual. Upper Saddle River, NJ: Prentice Hall.

McCabe, M., Heal, A., \& White, A. (2001). Integration of group response systems into teaching. Paper presented at the 5th International CAA Conference.

Nicol, D., \& Boyle, J. (2003). Peer instruction versus class-wide discussion in large classes: A comparison of two interaction methods in the wired classroom. Studies in Higher Education, 28(4), 457-473.

Nicol, D., \& Macfarlane-Dick, D. (2006). Rethinking formative assessment in HE: a theoretical model and seven principles of good feedback practice. Accessed 10th October 2008 from:

http://www.heacademy.ac.uk/resources/detail/ourwork/tla/web0015_rethinking_form ative_assessment_in_he.

Novak, G., Patterson, E., Gavrin, A. \& Wolfgang, C. (1999). Just-in-Time Teaching: Blending Active Learning and Web Technology. Upper Saddle River, NJ: PrenticeHall.

Roschelle, J., Penuel, W.R., \& Abrahamson, L. (2004). Classroom response and communication systems: Research review and theory. Paper presented at the Annual Meeting of the American Educational Research Association, San Diego, CA.

Russell, M. (2008). Using an electronic voting system to enhance learning and teaching. Accessed 11th August 2008 from:

http://www.engsc.ac.uk/downloads/scholarart/ee2008/p088-russell.pdf.

Simpson, V., \& Oliver, M. (2007). Electronic voting systems for lectures then and now: A comparison of research and practice. Australasian Journal of Educational Technology, 23(2), 187-208.

Simpson, V. \& Oliver, M (2002). Using electronic voting systems in lectures. UCL Internal report. Accessed 24th February 2008 from:

http://www.ucl.ac.uk/learningtechnology/examples/ElectronicVotingSystems.pdf.

Wilson, M. (2006). Evaluation of classroom response systems/voting tools. Falkirk Council Education Services. Accessed 21st November 2008 from:

http://www.reap.ac.uk/public/Resources/Falkirk_EVS_Evaluation.pdf.

Zhu, E. (2007). Teaching with clickers. Center for Research on Learning and Teaching Occasional Papers, 22. Accessed 26th February 2008 from: http://www.crlt.umich.edu/publinks/CRLT_no22.pdf. 


\section{Figure Captions}

Figure 1 Students using Turning Point handsets to register their responses to a question in class

Figure 2 Slide showing student response to a question on application of BODMAS to solving a fraction, with one of the options (option 1) highlighting a common student error

Figure 3 Chart showing the Engineering departments that the students who participated in this study are drawn from

Figure 4 Impact of handset drawbacks on its perceived usefulness

Figure $580 \%$ of students said EVS are 'useful' or 'very useful'

Figure 6 Overall advantageousness of handset use

Figure 7 Comparison of two other student solicitation methods with handsets

Figure 8 I mpact of handsets on student participation rates in class

\section{Tables}

\begin{tabular}{|l|l|}
\hline $\begin{array}{c}\text { Position } \\
1^{\text {st }} \text { (most } \\
\text { important) }\end{array}$ & $\begin{array}{l}\text { Checks whether I'm understanding course material as I thought I } \\
\text { was }\end{array}$ \\
\hline $2^{\text {nd }}$ & Allow learners to identify problem areas \\
\hline $3^{\text {rd }}$ & It makes lectures more interactive \\
\hline $4^{\text {th }}$ & Makes me think more about the course material during lectures \\
\hline $5^{\text {th }}$ & Gives me an idea of well everyone else is doing \\
\hline $6^{\text {th }}$ & Allows me to answer privately without others knowing how I voted \\
\hline $7^{\text {th }}$ & It's fun \\
\hline
\end{tabular}

Table 1 How benefits were ranked by students on the main questionnaire

\begin{tabular}{|l|l|l|l|l|l|l|l|}
\hline $\begin{array}{l}\text { Cohort's } \\
\text { Coursework Average } \\
\text { (in \%) }\end{array}$ & \multicolumn{3}{l|}{$\begin{array}{l}\text { Cohort's Exam } \\
\text { Average (in \%) }\end{array}$} & \multicolumn{2}{l|}{$\begin{array}{l}\text { Cohort's Overall } \\
\text { Average (in \%) }\end{array}$} & $\begin{array}{l}\text { \% of Students } \\
\text { Failed }\end{array}$ \\
\hline $06 / 7$ & $07 / 8$ & $06 / 7$ & $07 / 8$ & $06 / 7$ & $07 / 8$ & $06 / 7$ & $07 / 8$ \\
\hline 81.3 & 58.9 & 59.2 & 62.0 & 63.2 & 60.3 & 13.8 & 14.9 \\
\hline
\end{tabular}

Table 2 Data showing the average grades of students on a second-year Engineering mathematics course at Loughborough University over a two-year period 
Figures

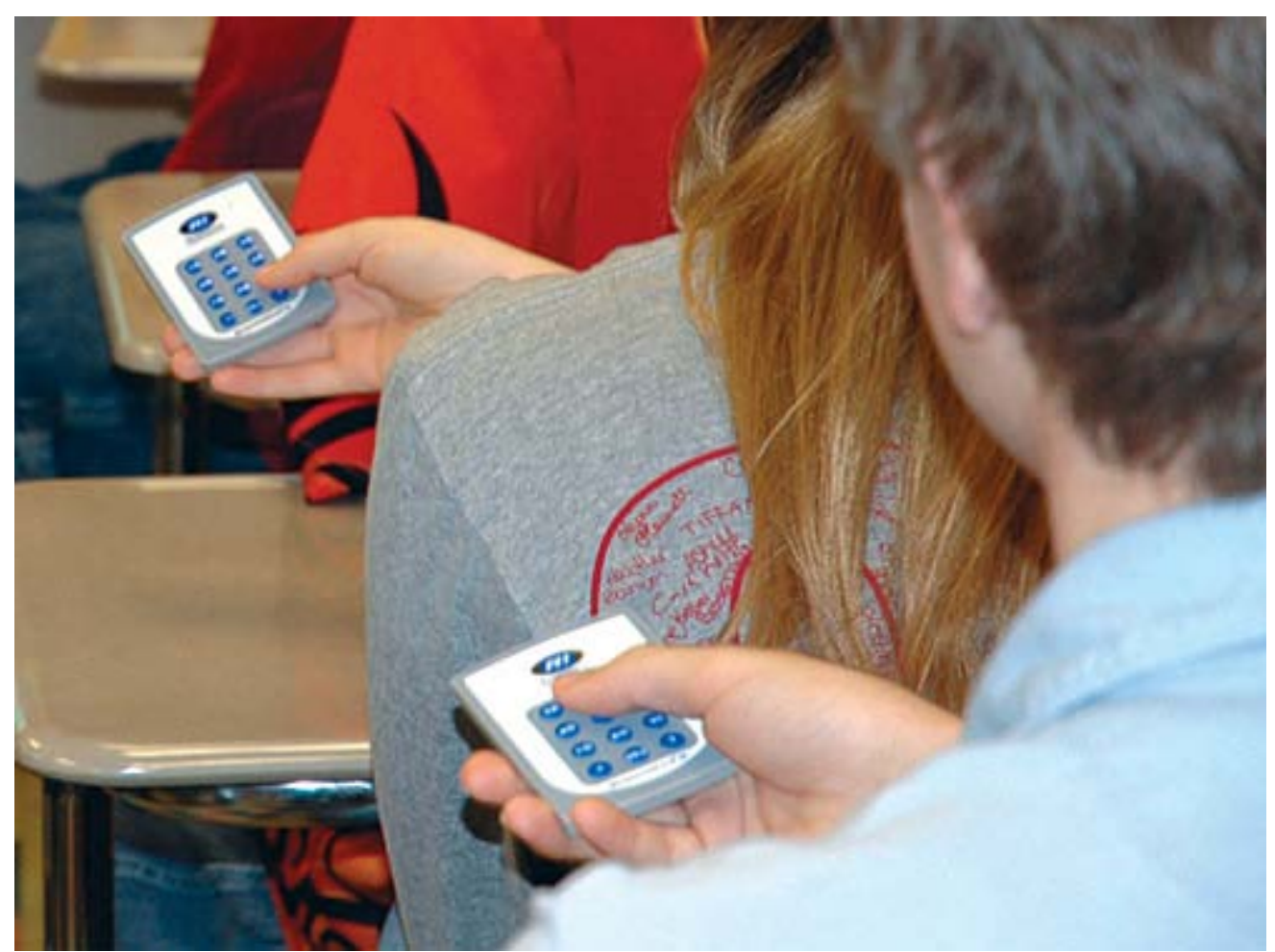

Which diagram best represents the region of integration of

$$
\int_{0}^{1} \int_{y}^{1}(y+x) d x d y
$$
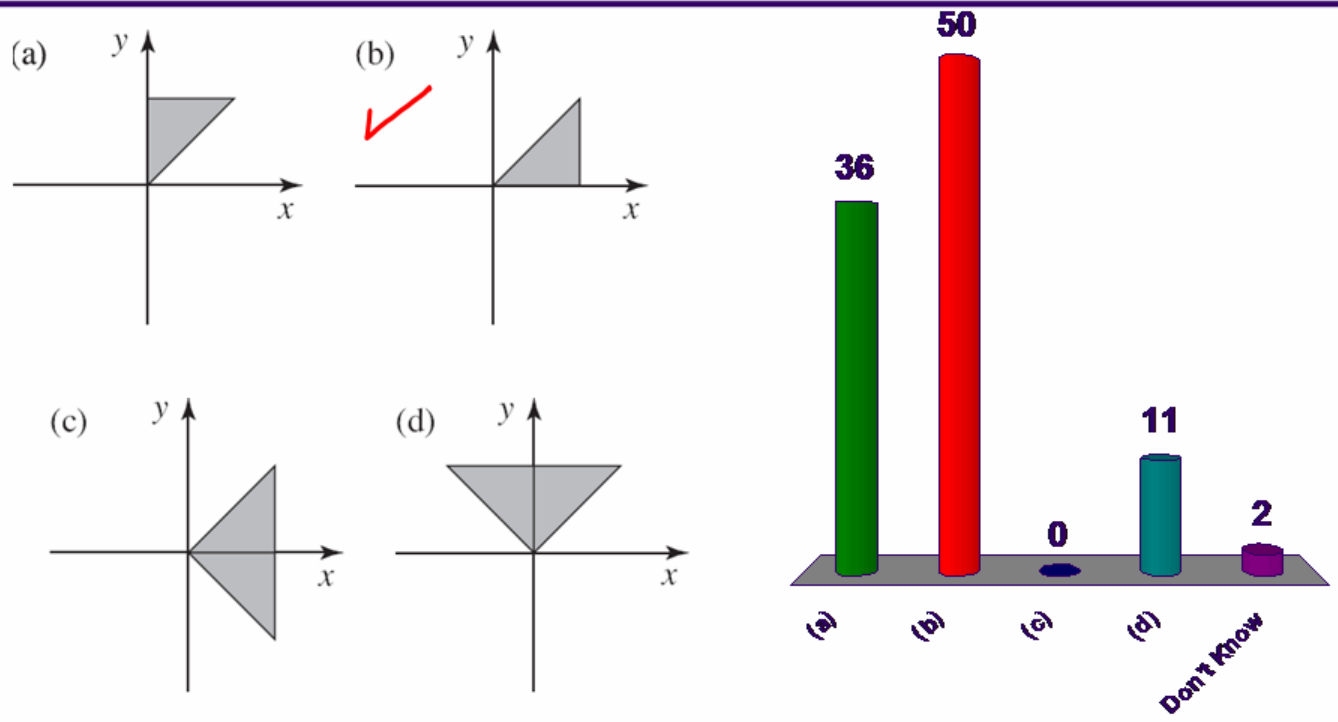


\section{Student Respondents by Department}

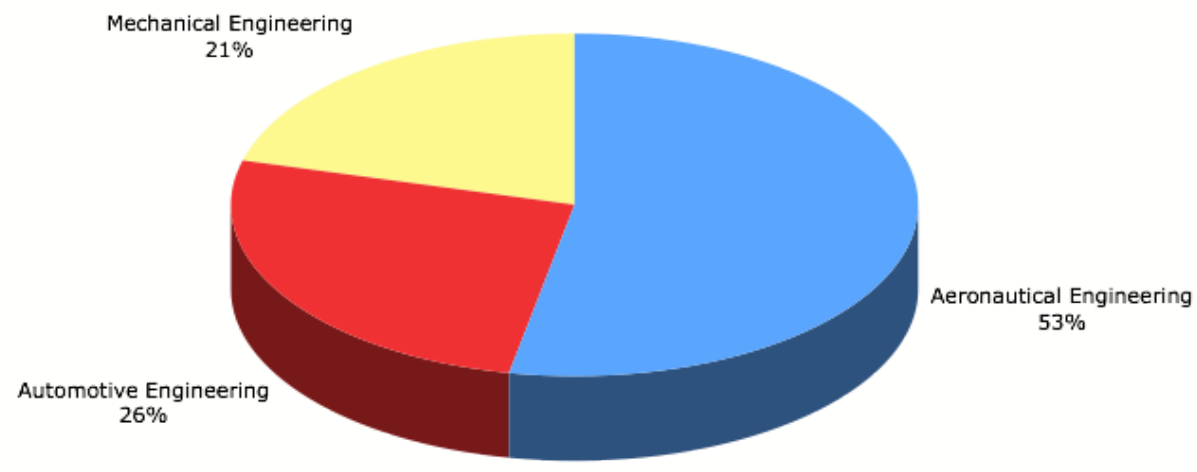

Impact of Handset Drawbacks on Usefulness

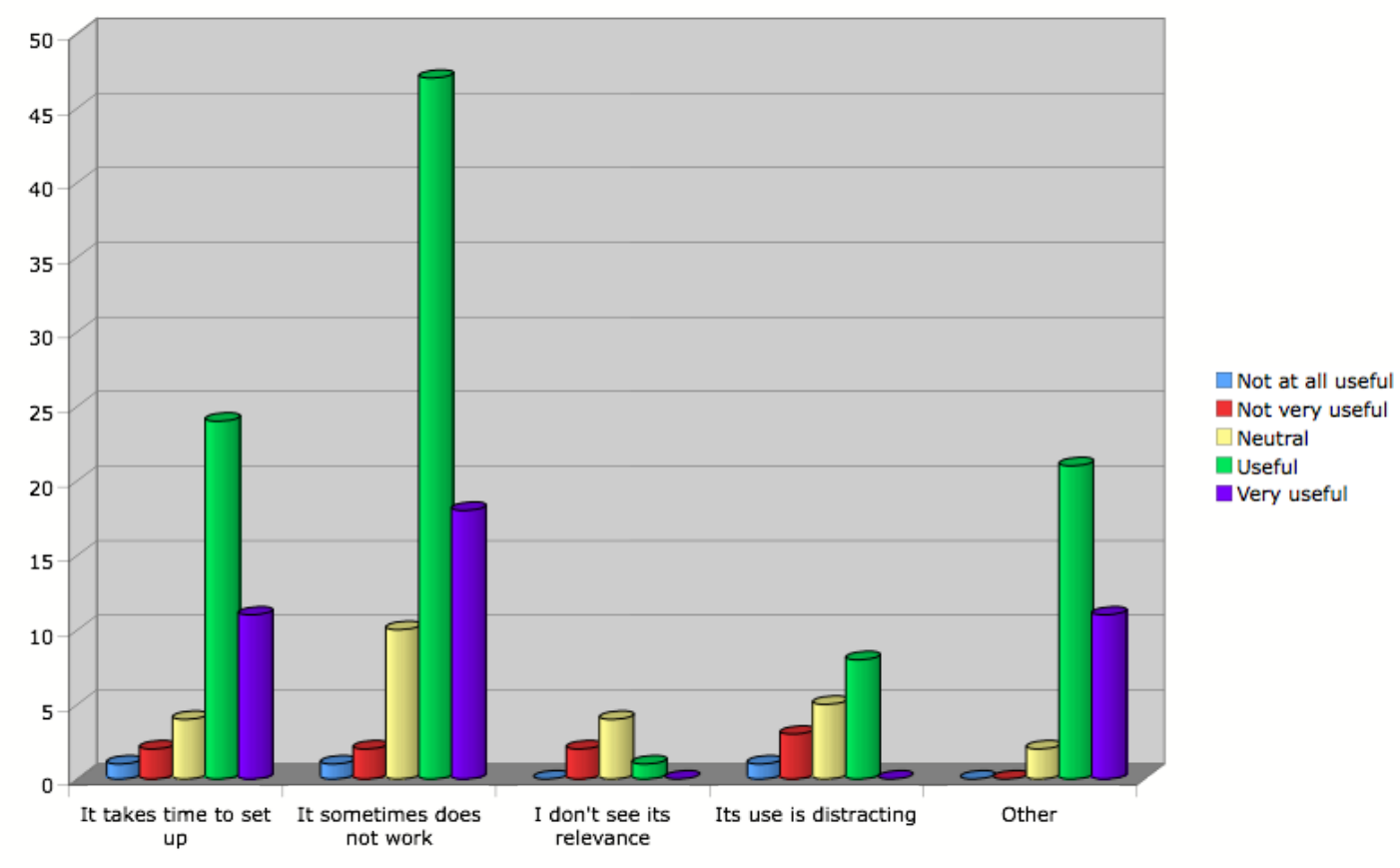




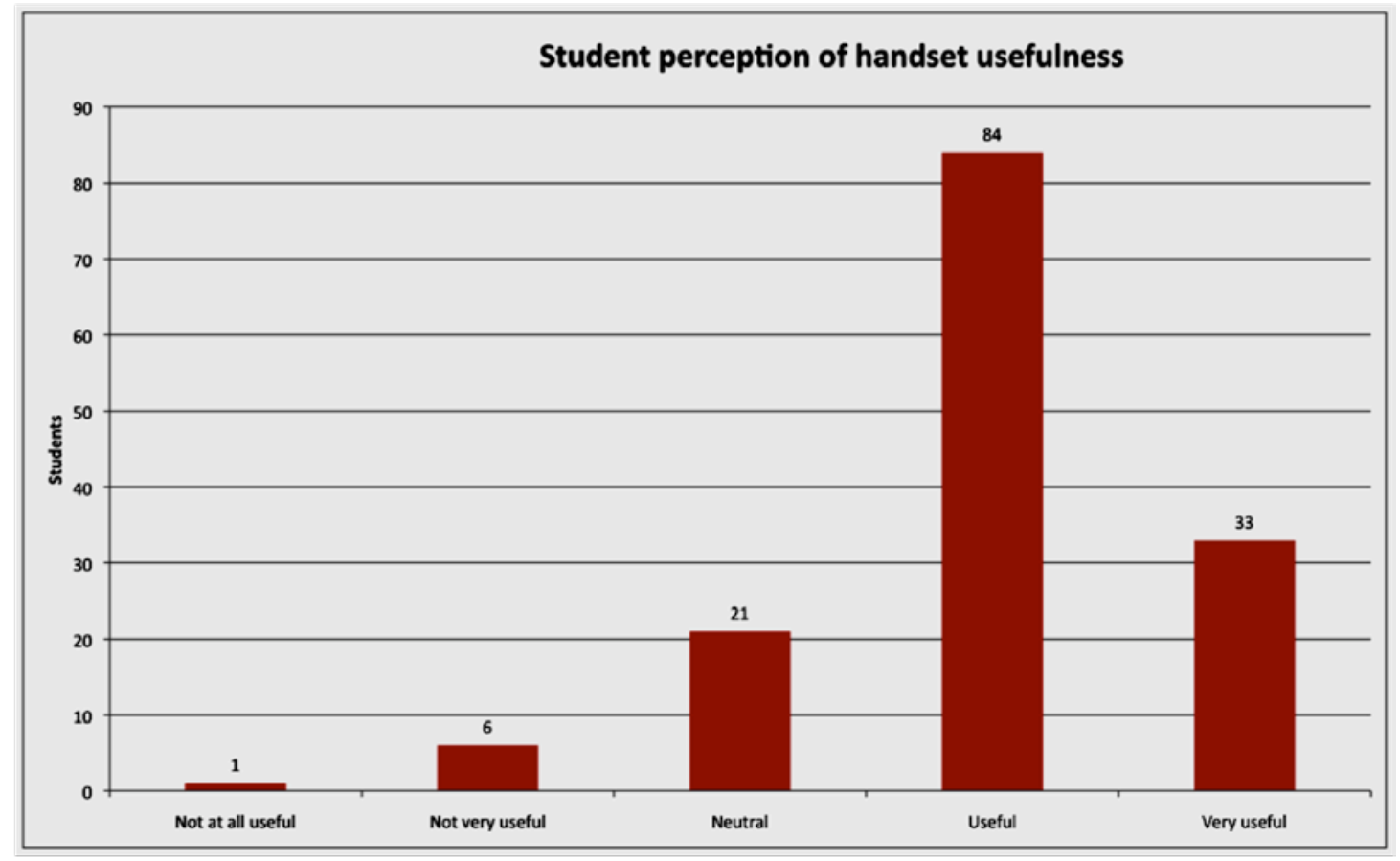

Overall Advantageousness

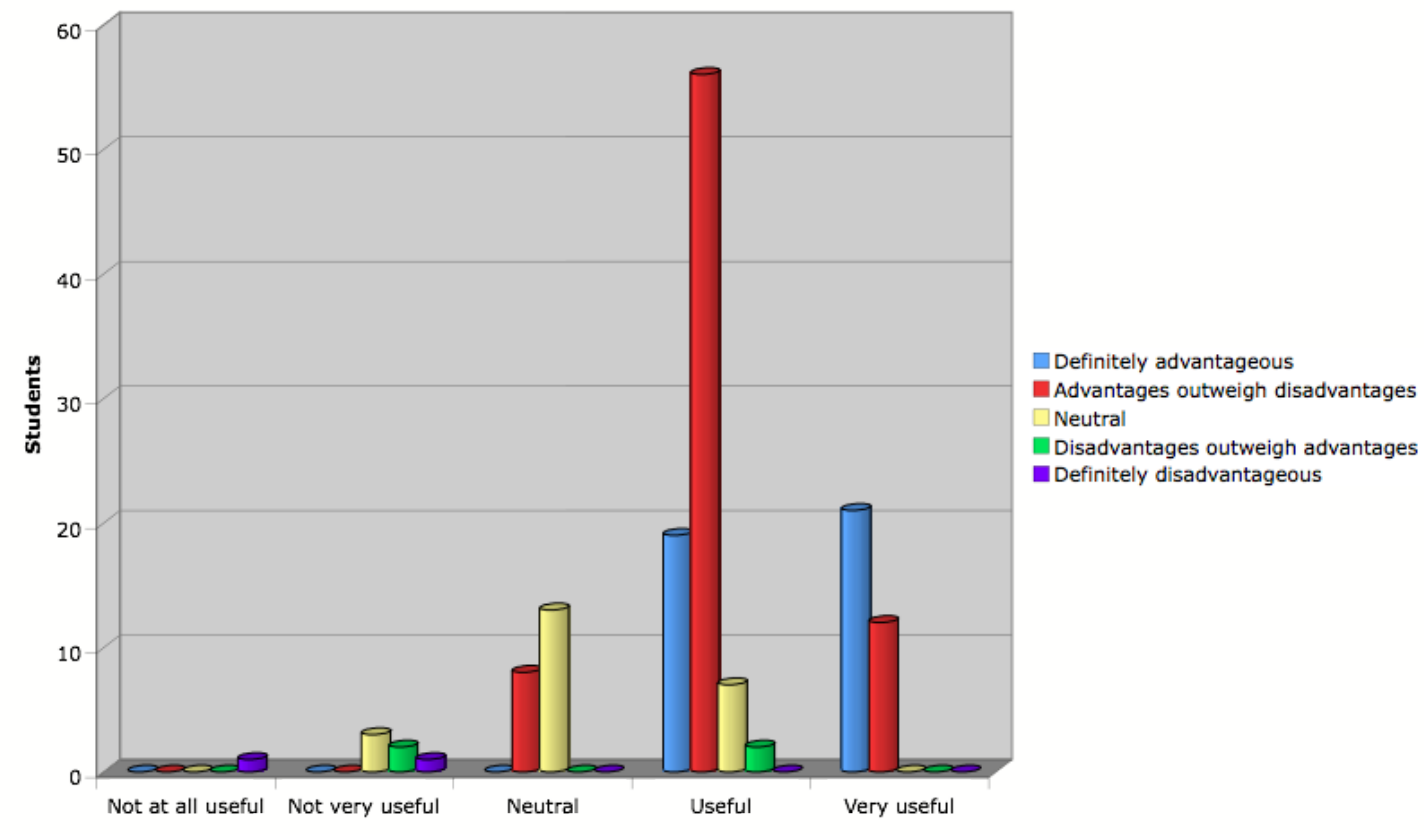



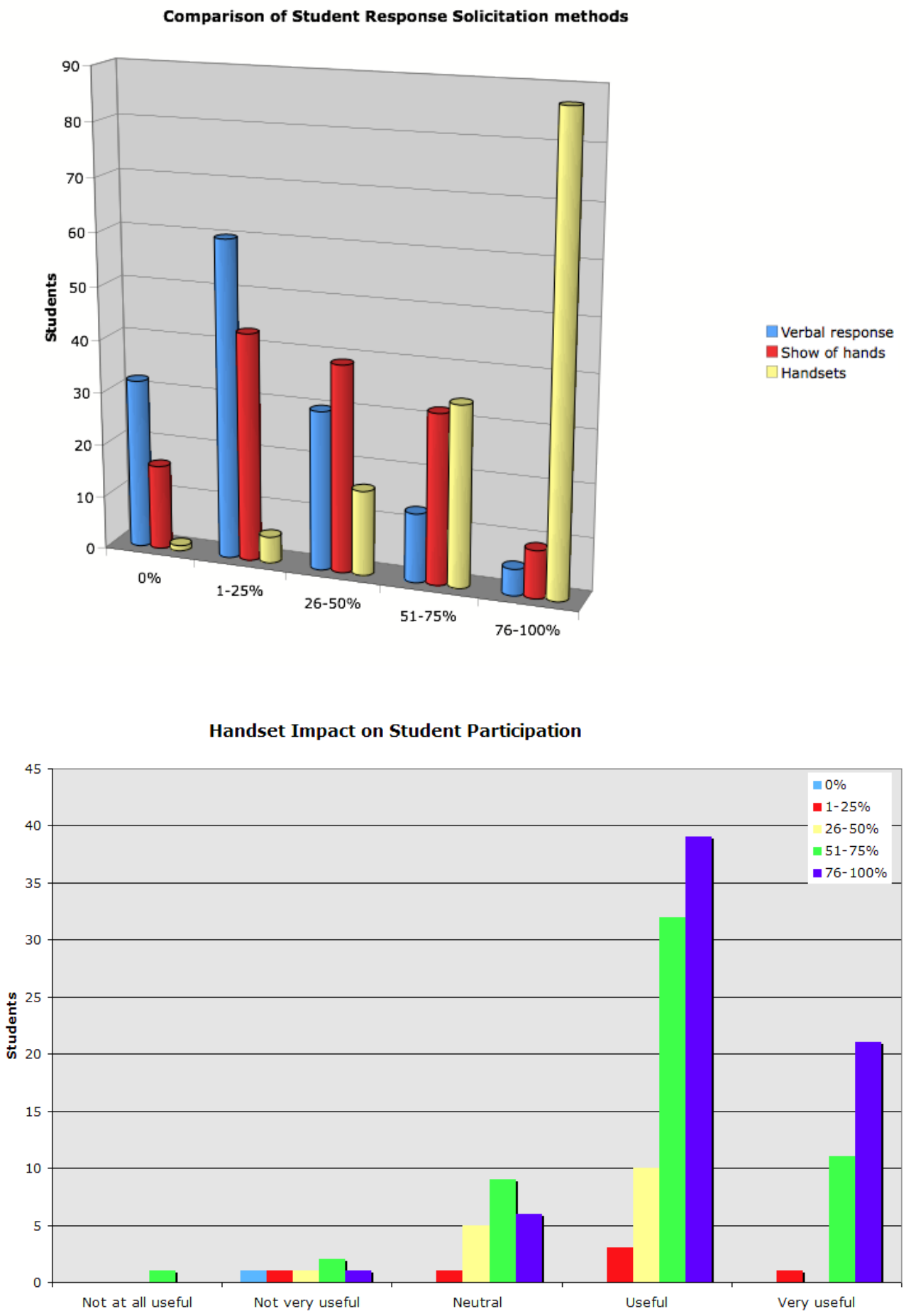